\title{
RANCANG BANGUN PURWARUPA ALAT MONITORING DAN KONTROL BEBAN SATU FASA BERBASIS IOT (INTERNET OF THINGS)
}

\author{
Afandi Amir ${ }^{*}$, Arief Marwanto, dan Dedi Nugroho \\ Program Studi Teknik Elektro, Universitas Islam Sultan Agung \\ Jl. Raya Kaligawe Km. 4, Semarang, Indonesia \\ ${ }^{*}$ Email :afandiamir@std.unissula.ac.id
}

\begin{abstract}
Abstrak
Pemanfaatan teknologi membuat tindakan-tindakan mematikan dan menghidupkan lampu ataupun perangkat elektronik lainnya dapat dilakukan secara semi-otomatis dan otomatis. Salah satu teknologi tersebut yaitu Internet of Things atau biasa disingkat dengan kata IoT. Internet of Things (IoT) membuat perangkat saat ini mampu bertukar informasi melalui jaringan internet. Oleh karena itu diusulkan monitoring daya dan kontrol beban 1 fase berbasis Internet of Things (IoT), dimana data hasil perekaman akan dikirim ke basis data yang telah disediakan platform yang bersifat open source melalui jaringan internet. Hasil yang dicapai berupa purwarupa alat yang mampu membaca nilai tegangan, arus, daya dan faktor daya menggunakan mikrokontroler Arduino Nano dengan sensor arus ZMCT103C dan Trafo $220 \mathrm{~V}-9 \mathrm{~V}$ yang digunakan sebagai sensor tegangan dengan nilai kesalahan pembacaan tegangan, arus, daya dan faktor daya beban satu fase dengan beban yang bervariasi rata-rata tidak lebih dari $5 \%$.
\end{abstract}

Kata kunci : internet of things, IoT, monitoring, kontrol beban

\begin{abstract}
The utilization of technology makes it easier to turn on or off lights or other electronic devices automatically or semiautomatically. One such technology is the Internet of Things or commonly abbreviated as IoT. Internet of Things (IoT) makes today's devices capable of exchanging information over the internet network. Therefore, it is proposed to monitor the power and to control the load of 1-phase circuitry based on Internet of Things (IoT), where the data of the recording to be sent to the database provided by open source platform through internet network. The result was a prototype device which is capable of reading voltage, current, power and power factor using Arduino Nano microcontroller with ZMCT103C current sensor and $220 \mathrm{~V}-9 \mathrm{~V}$ transformer. used as voltage sensor. The measurement shows that the errors of reading value, current, power and power factor a one-phase load with an average load was less than $5 \%$.
\end{abstract}

Keywords : internet of things, IoT, monitoring, load control

\section{Pendahuluan}

Setiap perangkat yang dimiliki membutuhkan sumber daya berupa tenaga listrik. Penggunaan tenaga listrik terkadang kurang efisien dan efektif. Penggunaan listrik yang kurang efisien dan efektif dapat dikurangi melalui beberapa tindakan. Tindakan mematikan segala perangkat yang tidak digunakan dan mematikan perangkat sesuai dengan waktunya merupakan salah satu contohnya.

Pemanfaatan teknologi membuat tindakan-tindakan tersebut dapat dilakukan secara semi-otomatis dan otomatis. Salah satu teknologi tersebut yaitu Internet of Things atau biasa disingkat dengan kata IoT. Internet of Things (IoT) membuat perangkat saat ini mampu bertukar informasi melalui jaringan internet[1]. Istilah Internet of Things (IoT) sendiri pertama kali digunakan oleh Kevin Ashton saat presentasi pada tahun 1999[2].

Penelitian beberapa tahun terakhir memanfaatkan teknologi agar sakelar dapat dikontrol secara otomatis dan pembacaan daya pada beban direkam dan disimpan pada suatu komputer. Konsep sistem smarthome yang mampu memanajemen energi melalui monitoring dan penjadwalan perangkat melalui Zigbee dan manajemen dan otomatisasi pengontrolan penggunaan daya listrik menggunakan Arduino merupakan beberapa penelitian yang terkait [3], [4]. Penelitian tersebut masih terdapat celah kelemahan yakni monitoring dan kontrol dilakukan pada suatu komputer yang dijadikan sebagai suatu server dalam 
jaringan lokal serta komputer harus dalam kondisi selalu aktif untuk perekaman dan kontrol perangkat.

Dari kelemahan tersebut, diusulkan monitoring daya dan kontrol beban 1 fase berbasis Internet of Things (IoT), dimana data hasil perekaman akan dikirim ke basis data yang telah disediakan platform yang bersifat open source melalui jaringan internet.

\section{Metode}

\subsection{Teori Pendukung}

Besaran umumnya diekspresikan sebagai jumlah atau satuan dari suatu produk dan satuan sendiri merupakan suatu gambaran atau contoh yang digunakan sebagai referensi. Besaran listrik terdiri dari beberapa kuantitas. Kuantitas besaran listrik yang termasuk dalam besaran pokok yaitu arus listrik. Kuantitas besaran listrik selain dari arus listrik termasuk dalam besaran turunan [5].

Perbedaan potensial atau tegangan didefinisikan sebagai perubahan energi potensial dari muatan $\mathbf{q}$ yang dipindahkan dari titik A ke $\mathrm{B}$, dibagi dengan muatan. Satuan dari perbedaan potensial merupakan joule per coulomb, diganti menjadi volt setelah inovasi dari Alessandro Volta [6].

Sumber tegangan AC yang terukur merupakan nilai tegangan efektif. Tegangan AC efektif biasa disebut dengan $V_{r m s}$. $V_{r m s}$ merupakan jumlah daya $\mathrm{AC}$ yang menghasilkan efek yang sama dengan daya pada DC [7]. Berikut ini merupakan persamaan $V_{r m s}$ :

$V_{r m s}=V_{m} \frac{1}{\sqrt{2}}=V_{m} \times 0.7071$

Keterangan :

$V_{r m s}=$ Tegangan efektif

$V_{m}=$ Tegangan maksimal / Tegangan puncak

Tegangan melintasi berbagai jenis bahan pengantar adalah berbanding lurus kepada arus yang mengalir melalui bahan tersebut, di mana konstanta pembanding $\mathrm{R}$ dinamai resistansi (tahanan) [8], sesuai Hukum Ohm:

$v=i . R$

Keterangan :

$v=$ Tegangan

$i=$ Arus

$R=$ Resistansi

Namun, dalam rangkaian AC satu fasa yang memebentuk gelombang sinusoidal, arus yang terukur merupakan $I_{r m s}$. Berikut ini merupakan persamaannya :

$I_{r m s}=I_{m} \frac{1}{\sqrt{2}}=I_{m} \times 0.7071$

Keterangan :

$I_{r m s}=$ Arus efektif

$I_{m}=$ Arus maksimal / Arus puncak

Daya listrik merupakan energi yang dikeluarkan atau kerja yang dilakukan setiap detik oleh arus dalam satu ampere pada tegangan satu volt [9]. Daya pada sumber tegangan bolak-balik (AC - Alternating Current) berbentuk sinusioidal umumnya terdiri dari beberapa macam yaitu daya kompleks, daya aktif dan daya reaktif.

Untuk keperluan pengubahan tegangan dan arus AC, umumnya digunakan trafo. Umumnya konstruksi trafo terdiri dari dua buah kumparan yang terpisah. Kumparan tersebut terikat dengan medan magnet bersama atau mutual yang dibangkitkan dalam inti bahan magnetik. Inti magnetik terdiri dari tumpukan laminasi-laminasi baja yang tipis dengan ketebalan kisaran $0.35 \mathrm{~mm}$ untuk trafo $50 \mathrm{~Hz}[10]$.

\subsection{Development Kit untuk IoT}

Firmware open-source dan development kit yang mampu membantu untuk membuat prototipe produk IoT dalam beberapa baris script Lua [11]. NodeMcu berbasis mikrokontroller ESP8266 dan memiliki $128 \mathrm{~Kb}$ memori dan 4 MB sebagai penyimpanan. Nodemcu dapat digunakan melalui Arduino IDE dengan menambahkan library board yang telah dibuat oleh ESP8266 Opensource Community.

Dalam pengembangan IoT, Cayenne merupakan platform pertama pendukung pembangunan proyek IoT dengan konsep tarik dan letakkan atau dikenal dengan drag and drop yang mendukung pengembang, desainer dan teknisi untuk mengembangkan dengan cepat purwarupa dari alat dan membagi pengalaman dalam pembuatannya. Cayenne juga didesain untuk membantu para pengguna dalam membuat purwarupa alat IoT dan menjadikan dalam bentuk suatu produksi massal.

Terdapat beberapa komponen utama yang terdapat pada platform ini di antaranya Cayenne App, Cayenne Online Dashboard, Cayenne Cloud dan Cayenne Agent.

\subsection{Perancangan Perangkat Keras (Hardware)}

Perancangan perangkat keras meliputi pemilihan perangkat keras yang digunakan serta perancangan desain dan tata letak komponen breadboard atau project board dan penyambungan/ pematerian komponen.

Inti dari rangkaian hardware adalah pada penggunaan Arduino Nano. Komponen ini merupakan sebuah mikrokontroller yang berukuran kecil, dan lengkap, serta cocok untuk dipasangkan pada papan proyek (breadboard) [12]. Arduino Nano berbasis ATmega 328 (Arduino Nano 3.x) fungsinya sama seperti Arduino Duemilanove, akan tetapi dalam bentuk berbeda. Blok diagram purwarupa alat perekaman nilai tegangan dan arus beban 1 fase berbasis IoT ditunjukkan pada Gambar 1. 


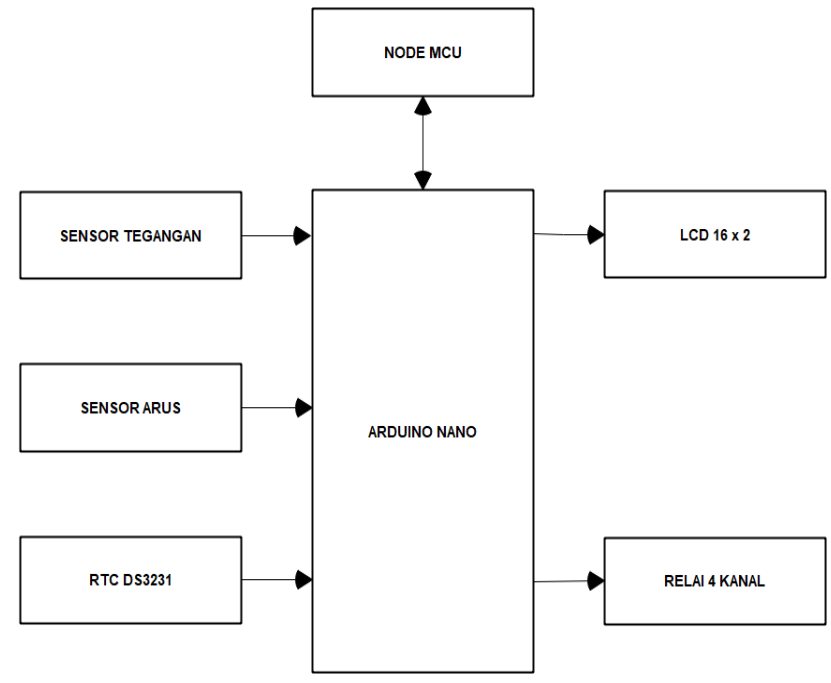

Gambar 1. Blok diagram purwarupa alat perekaman nilai tegangan dan arus beban 1 fase berbasis IoT

Pada pembuatan sensor tegangan digunakan trafo 220 - 9 $\mathrm{V}$ dengan arus $1 \mathrm{~A}$. Trafo tersebut digunakan agar tegangan tetap berada dalam bentuk sinusoidal. Bentuk sinosoidal tegangan dalam bentuk tegangan yang rendah dibutuhkan sebelum dihubungkan ke mikrokontroler. Gambar 2 merupakan skema rangkaian sensor tegangan.

Dari rumus pembagi tegangan dapat diketahui nilai resistor yang akan digunakan. Untuk menentukan nilai resistor $\mathbf{R}_{2}$ harus ditentukan nilai resistansi $\mathrm{R}_{1}$ terlebih dahulu. Nilai $\mathrm{R}_{1}$ yang ditentukan sebesar $10 \mathrm{k} \Omega$, maka :

$$
\begin{aligned}
& 1.767 \mathrm{~V}=9 \mathrm{~V} \times \frac{10000 \Omega}{10000 \Omega+R_{2}} \\
& 17670 \mathrm{~V} \Omega+1.767 \mathrm{~V} R_{2}=90000 \mathrm{~V} \Omega \\
& R_{2}=\frac{90000 \mathrm{~V} \Omega-17670 \mathrm{~V} \Omega}{1.767 \mathrm{~V}} \\
& R_{2}=40.933 \mathrm{k} \Omega
\end{aligned}
$$

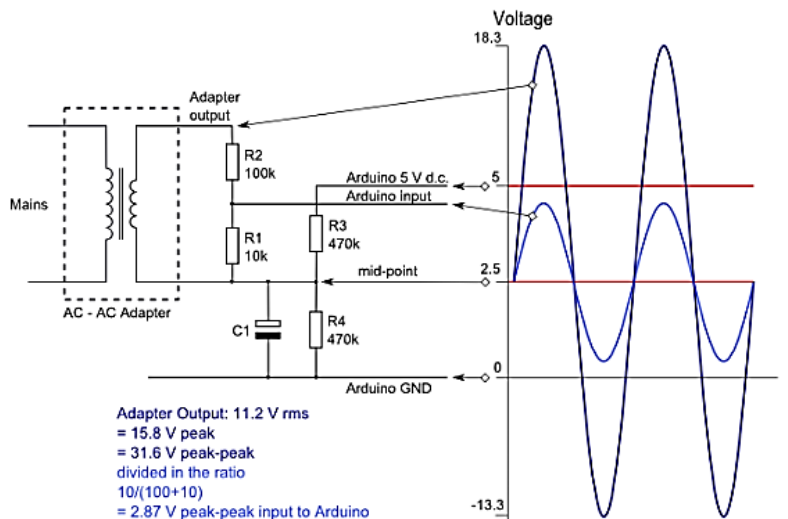

Gambar 2. Skema rangkaian sensor tegangan dan diagram bentuk gelombang tegangan sinusoidal menuju ke mikrokontroler
Dari hasil tersebut didapatkan nilai $R_{2}=40.933 \mathrm{k} \Omega$, untuk mendapatkan resistor di pasaran dengan nilai tersebut sangat sulit. Oleh karena itu, nilai resistor $R_{2}$ diubah menjadi $R_{2}=100 \mathrm{k} \Omega$. Dari nilai tersebut berpengaruh pada besarnya tegangan keluaran menjadi $V_{\text {out }}=0.818 \mathrm{~V}$ dan tegangan puncak $V_{p}=1.28 \mathrm{~V}$. Hasil tersebut masih berada di bawah dari tegangan puncak maksimal dan tegangan keluaran maksimal maka resistor tersebut dapat digunakan.

Perancangan dan pembuatan untuk sensor arus menggunakan sensor ZMCT103C keluaran Nanjing Zeming Electronics Co., Ltd., di China. Sensor tersebut merupakan trafo dengan bentuk ring-core rasio 1000:1 serta keluaran arus maksimal sebesar $5 \mathrm{~mA}$. Sensor ZMCT103C mampu mengukur arus tegangan AC satu fase [11]. Adapun kelebihannya di antaranya dimensi kecil, akurasi tinggi, mampu mengukur sampai dengan 5A dan keluaran yang proporsional berupa arus AC.

Rangkaian sensor arus (seperti ditunjukkan pada Gambar 3) memiliki kesamaan seperti rangkaian sensor tegangan. Diperlukan rangkaian pembagi tegangan serta penggeser titik $0 \mathrm{~V}$ ke $2,5 \mathrm{~V}$ agar dapat dibaca pada mikrokontroler.

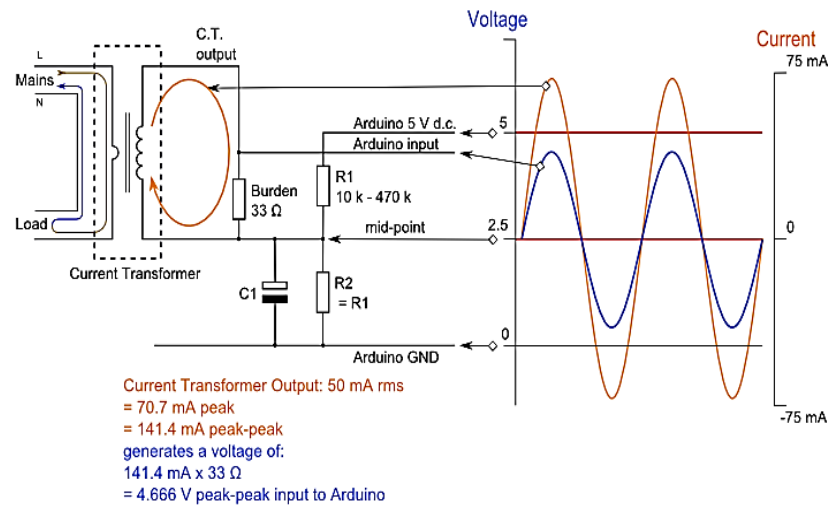

Gambar 3. Skema rangkaian sensor arus dan diagram bentuk gelombang tegangan sinusoidal menuju ke mikrokontroler

Menjaga tegangan puncak maksimal dalam pengukuran di bawah 2,5V maka dibutuhkan rangkaian pembagi tegangan serta resistor sebagai beban (burden resistor). Dengan menggunakan persamaan 2.3 berdasarkan Hukum Kirchoff maka dapat ditentukan nilai resistor beban, sebagai berikut

$2,5 V=5 m A \times R_{\text {burden }}$

$R_{\text {burden }}=\frac{2,5 \mathrm{~V}}{5 m \mathrm{~A}}$

$R_{\text {burden }}=500 \Omega$

Nilai resistansi maksimal untuk resistor beban sebesar $500 \Omega$, agar nilai keluaran tegangan tetap berada di bawah 2,5 V dengan nilai arus keluaran maksimal sensor sebesar 
$5 \mathrm{~mA}$ maka nilai resistansi yang dipasang sebaiknya kurang dari $500 \Omega$.

Nilai resistansi $500 \Omega$ sangatlah sulit sehingga resistor yang digunakan yaitu $330 \Omega$ dan $22 \Omega$ yang dihubungkan seri sehingga nilai total resistansi yaitu $352 \Omega$. Nilai resistansi tersebut masih berada dalam batasan aman. Apabila nilai $R_{\text {burden }}=352$ maka nilai $V_{\text {out }}$ maksimal sebesar $1.76 \mathrm{~V}$.

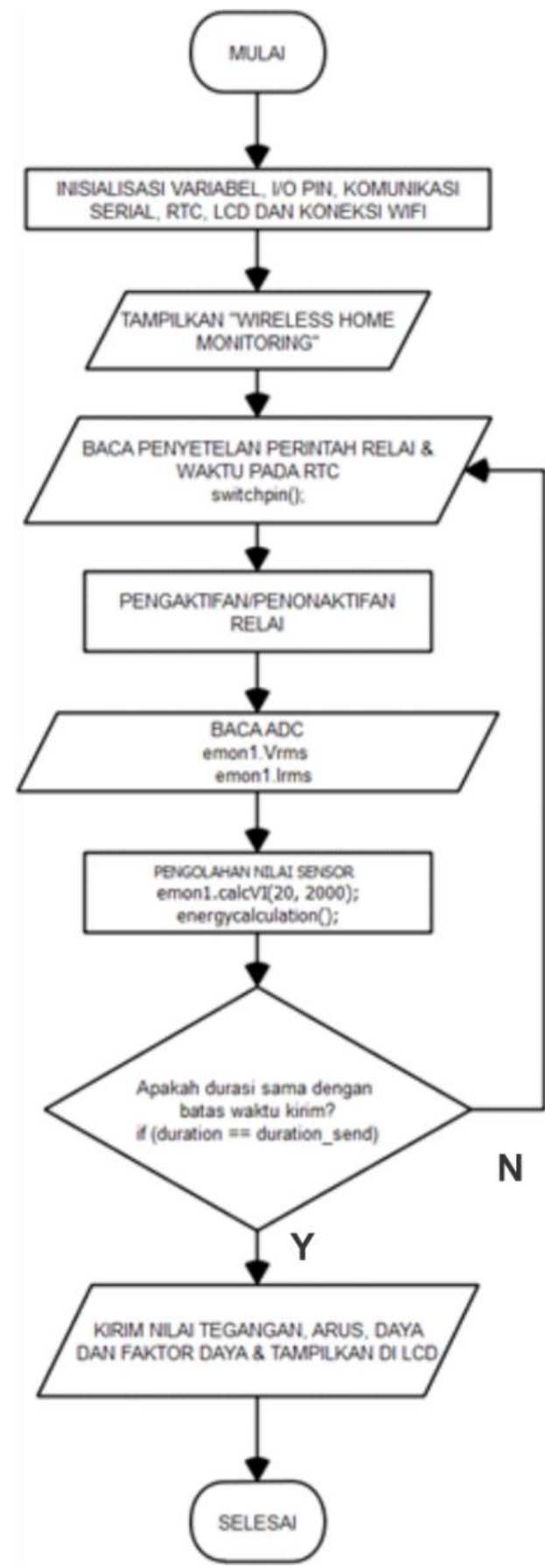

Gambar 4 Flowchart program

\subsection{Perancangan Perangkat Lunak (Software)}

Pada perancangan perangkat lunak dilakukan pembuatan program untuk mengakses sensor dan modul, mengakses komunikasi antara Arduino Nano dan NodeMCU, membuat program kalibrasi pembacaan nilai tegangan dan nilai arus, membuat program konektivitas antara perangkat ke jaringan internet, dan pembuatan program pengiriman data pembacaan ke basis data platform dan pembuatan program pengontrolan dari web platform ke Arduino Nano.

Aliran algoritma atau proses yang menampilkan langkahlangkah dari suatu program diperlukan suatu flowchart. Untuk menjelaskan algoritma pemrograman disajikan dalam flowchart pada Gambar 4.

Setiap kanal virtual yang terkirim dapat diwakili oleh suatu tampilan widget. Widget pada Cayenne Online Dashboard bermacam-macam, terdapat bentuk tampilan hanya berupa nilai, tampilan gauge, tampilan grafik garis, tampilan tombol dan tampilan tombol geser.

\section{Hasil dan Analisa}

3.1. Pengujian dan Analisis Pengukuran Tegangan, Arus, Daya dan Faktor Daya

Pengujian ini dengan memberikan beban yang bervariasi dan diamati serta dikontrol langsung melalui Cayenne Online Dashboard. Adapun beban yang digunakan yaitu lampu TL $23 \mathrm{~W}$, lampu pijar $40 \mathrm{~W}$, lampu pijar $60 \mathrm{~W}$ dan kipas angin dengan daya sebesar $50 \mathrm{~W}$. Tabel 1 merupakan hasil dari pembacaan nilai tegangan, arus, daya dan faktor daya dari purwarupa alat. Adapun data hasil pengukuran menggunakan alat ukur Hioki Model 3183 ditunjukkan pada Tabel 2.

Tabel 1. Nilai tegangan, arus, daya dan faktor daya purwarupa alat

\begin{tabular}{|c|c|c|c|c|c|}
\hline \multirow{2}{*}{ No. } & \multirow{2}{*}{ Jenis Beban } & Tegangan & Arus & Daya & \multirow{2}{*}{$\begin{array}{l}\text { Faktor } \\
\text { Daya }\end{array}$} \\
\hline & & V & $\mathrm{mA}$ & W & \\
\hline 1. & Tanpa beban & 220.71 & 17.14 & 1.3 & 0.34 \\
\hline 2. & $\begin{array}{c}\text { Lampu TL } \\
23 \mathrm{~W}\end{array}$ & 221.34 & 168.85 & 27.33 & 0.73 \\
\hline 3. & $\begin{array}{l}\text { Lampu pijar } \\
40 \mathrm{~W}\end{array}$ & 221.92 & 185.03 & 41.16 & 1.00 \\
\hline 4. & $\begin{array}{l}\text { Lampu pijar } \\
60 \mathrm{~W}\end{array}$ & 221.57 & 266.5 & 59.53 & 1.00 \\
\hline 5. & $\begin{array}{l}\text { Kipas angin } \\
50 \mathrm{~W}\end{array}$ & 220.63 & 255.56 & 55.99 & 0.99 \\
\hline
\end{tabular}


Tabel 2. Nilai tegangan, arus, daya dan faktor daya Hioki Model 3183

\begin{tabular}{|c|c|c|c|c|c|}
\hline \multirow{2}{*}{ No. } & \multirow{2}{*}{ Jenis Beban } & Tegangan & Arus & Daya & \multirow{2}{*}{$\begin{array}{l}\text { Fakto } \\
\text { Daya }\end{array}$} \\
\hline & & V & $\mathrm{mA}$ & $w$ & \\
\hline 1. & Tanpa beban & 220 & 12.8 & 1.19 & 0.42 \\
\hline 2. & $\begin{array}{c}\text { Lampu TL } \\
23 W\end{array}$ & 220 & 166 & 26.38 & 0.72 \\
\hline 3. & $\begin{array}{l}\text { Lampu pijar } \\
40 \mathrm{~W}\end{array}$ & 222 & 182 & 41.6 & 1.00 \\
\hline 4. & $\begin{array}{l}\text { Lampu pijar } \\
60 \mathrm{~W}\end{array}$ & 221 & 264 & 60.3 & 1.00 \\
\hline 5. & $\begin{array}{c}\text { Kipas angin } \\
50 \mathrm{~W}\end{array}$ & 221 & 253 & 56.8 & 1.00 \\
\hline
\end{tabular}

Pada analisa pengukuran tegangan, arus, daya dan faktor daya dilakukan perhitungan nilai kesalahan (error) dari nilai tabel tersebut. Nilai error diambil dari persentase perbandingan nilai pembacaan alat ukur Hioki model 3183 dengan purwarupa alat. Berikut tabel perhitungan nilai error pembacaan tegangan, arus, daya dan faktor daya :

Tabel 3. Perhitungan nilai error pembacaan tegangan, arus, daya dan faktor daya

\begin{tabular}{cccccc}
\hline \multirow{2}{*}{ No. } & \multirow{2}{*}{ Jenis Beban } & \multicolumn{4}{c}{ Error (\%) } \\
\cline { 3 - 6 } & & $\mathbf{V}$ & $\mathbf{I}$ & $\mathbf{P}$ & $\mathbf{P F}$ \\
\hline 1. & Tanpa beban & 0.32 & 33.91 & 9.24 & 18.68 \\
2. & Lampu TL & 0.61 & 1.72 & 3.60 & 1.24 \\
3. & $\begin{array}{c}\text { Lampu pijar } \\
\text { 40W }\end{array}$ & 0.04 & 1.66 & 1.06 & 0 \\
4. & $\begin{array}{c}\text { Lampu pijar } \\
60 \mathrm{~W}\end{array}$ & 0.26 & 0.95 & 1.28 & 0 \\
5. & $\begin{array}{c}\text { Kipas angin } \\
50 \mathrm{~W}\end{array}$ & 0.17 & 1.01 & 1.43 & 0.7 \\
\hline
\end{tabular}

Nilai kesalahan pembacaan tegangan, arus, daya dan faktor daya beban satu fase dengan beban yang bervariasi ratarata tidak lebih dari $5 \%$.

\subsection{Pengujian dan Analisa Kontrol Beban}

Hasil dari pengujian kontrol beban telah sesuai dengan perancangan kontrol beban menggunakan modul relai 4 kanal. Tiap beban dapat dikontrol melalui Cayenne Online Dashboard dan Cayenne Android App. Pada saat proses kontrol beban masih terdapat waktu tunda kurang lebih 1 detik. Hal tersebut dapat disebabkan oleh lamanya waktu proses pengolahan data kontrol pada NodeMCU dan Arduino Nano. Selain hal tersebut, koneksi jaringan internet juga dapat mempengaruhi waktu pengiriman dan penerimaan data kontrol.

\section{Kesimpulan}

Kesimpulan yang diperoleh dari hasil penelitian ini dipaparkan sebagai berikut ini. Purwarupa alat mampu membaca nilai tegangan, arus, daya dan faktor daya menggunakan mikrokontroler Arduino Nano dengan sensor arus ZMCT103C dan Trafo $220 \mathrm{~V}-9 \mathrm{~V}$ yang digunakan sebagai sensor tegangan dengan nilai kesalahan pembacaan tegangan, arus, daya dan faktor daya beban satu fase dengan beban yang bervariasi rata-rata tidak lebih dari $5 \%$.

Purwarupa alat mampu terhubung platform open source (Cayenne menggunakan NodeMCU sebagai pengolah koneksi melalui jaringan internet yang diprogram melalui Arduino IDE. Nilai pembacaan tegangan, arus, daya dan faktor daya serta kontrol beban mampu ditampilkan dan dikontrol melalui web platform open source (Cayenne Online Dashboard dan Cayenne Android App).

Untuk pengembangan ke depannya data logger dapat digunakan sebagai penyimpan sementara apabila koneksi internet putus ataupun lambat.

\section{Referensi}

[1] A. Al-Fuqaha, M. Guizani, M. Mohammadi, M. Aledhari, dan M. Ayyash. "Internet of things: A survey on enabling technologies, protocols, and applications." IEEE Communications Surveys \& Tutorials, vol 17, no. 4, hal. 2347-2376, 2015.

[2] R. Buyya dan A. Vahid Dastjerdi, Ed., Internet of Things Principles and Paradigms. Morgan Kaufmann, 2016.

[3] F. Baig, A. Mahmood, N. Javaid, S. Razzaq, N. Khan, dan Z. Saleem, "Smart Home Energy Management System for Monitoring and Scheduling of Home Appliances Using Zigbee," Journal of Basic and Applied Science Research, vol. 3, no. 5, hal. 880-891, 2013.

[4] A. Pattisahusiwa, M. Delia, Y. Mardiansyah, dan Hendro, "Manajemen dan Otomatisasi Pengontrolan Penggunaan Daya Listrik secara Masal Menggunakan Jaringan Arduino Uno," Proseding Seminar Kontribusi Fisika 2014 (SKF 2014), vol. 2014, no. March 2015, hal. 17-18, 2014.

[5] AMP Brookes, Basic Electric Circuits: Pergamon International Library of Science, Technology, Engineering and Social Studies. Elsevier, 2014.

[6] S. J. Ling, J. Sanny, dan W. Moebs, University Physics Volume 2. Texas: Open Stax, 2016.

[7] A.G. Expósito, , A.J. Conejo, dan C. Canizares, Electric energy systems: analysis and operation. CRC Press, 2016.

[8] W. H. Hayt. Jr. dan J. E. Kemmerly, Rangkaian Listrik. Penerbit Erlangga.1999.

[9] C. Cekdin dan T. Barlian, Rangkaian Listrik. Penerbit ANDI, 2013.

[10] M. Abdurohman, A.G. Putrada, S. Prabowo, C.W. Wijiutomo, dan A. Elmangoush. "M2M Device Connectivity Framework." International Journal on Electrical Engineering and Informatics vol 9, no. 3 hal. 441-454, 2017.

[11] Soebagio, Transformator. Surabaya: ITS PRESS, 2012.

[12] M. Nithya, "System Automation And Production Monitoring In Industries Using Arduino With IoT Technology." International Journal Of Engineering And Computer Science vol. 5, no. 3, hal. 16029-16032 2016.

[13] Nodemcu Development Team, "NodeMcu -- An opensource firmware based on ESP8266 wifi-soc."

[Daring]. Tersedia pada:

http://www.nodemcu.com/index_en.html. [Diakses: 26Des-2016]. 